\title{
Three New Compounds Derived from Nitrofurantoin: X-Ray Structures and Hirshfeld Surface Analyses
}

\author{
Hao Wang, Hongping Xiao, Na Liu, Bo Zhang, Qian Shi* \\ Nanomaterials \& Chemistry Key Laboratory, College of Chemistry and Materials Engineering, Wenzhou \\ University, Wenzhou, China \\ Email: ${ }^{*}$ shiq@wzu.edu.cn
}

Received 12 March 2015; accepted 21 July 2015; published 24 July 2015

Copyright (C) 2015 by authors and Scientific Research Publishing Inc.

This work is licensed under the Creative Commons Attribution International License (CC BY). http://creativecommons.org/licenses/by/4.0/

\begin{abstract}
The polymorphism of nitrofurantoin (NF), 1), the cocrystals of NF:2,2'-bipyridyl = 2:1, 2) and NF: 1,10-phenanthroline $=1: 1,3$ ) have been prepared and characterized. The crystal structure analyses show that there are various weak forces among the molecules, such as $\mathrm{C} / \mathrm{N}-\mathrm{H} \cdots \mathrm{O}, \mathrm{N}-\mathrm{H} \cdots \mathrm{N}$ hydrogen bond interactions and $\pi \cdots \pi$ /lone pair stacking interactions, which play a key role in the assembly of supramolecular networks. A thorough analysis of Hirshfeld surfaces and fingerprint plots facilitates a comparison of intermolecular interactions in $1-3$, which are crucial in building supramolecular architectures.
\end{abstract}

\section{Keywords}

Nitrofurantoin Co-Crystals, Intermolecular Interactions, X-Ray Structures, Hirshfeld Surface

\section{Introduction}

Noncovalent weak intermolecular interactions have gained much attention due to their unquestionable role in various chemical, physical, and biological processes [1]-[6]. Among these interactions, the hydrogen bonds are the most important in view of their energy and directionality [7]. Nitrofurantoin (NF) is an antibacterial drug and widely used for the treatment of urinary tract infections [8], however, a series of potential problems that occur in using such drugs, such as photosensitive [9], low solubility and low permeability [10]. In recent years, some progresses in improving these insufficient have been made according to crystal engineering through exploring the molecular recognition between NF and co-formers [11]-[13]. Considering the planar structure of NF, the

\footnotetext{
*Corresponding author.
}

How to cite this paper: Wang, H., Xiao, H.P., Liu, N., Zhang, B. and Shi, Q. (2015) Three New Compounds Derived from Nitrofurantoin: X-Ray Structures and Hirshfeld Surface Analyses. Open Journal of Inorganic Chemistry, 5, 63-73. 
molecules with delocalization $\Pi$ bonds, such as 2,2'-bipyridyl (bipy) and 1,10-phenanthroline (phen), were selected to form cocrystals with NF through molecular recognition. Fortunately, one new polymorphism [14] of NF and two new cocrystals, NF:bipy $=2: 1$ (2) and NF:phen $=1: 1$ (3), were obtained. As anticipated, singlecrystal X-ray structural analyses of compounds 1-3 revealed the generation of extended supramolecular networks by means of hydrogen bond interactions, $\pi \cdots \pi$ interactions and lone pair $\cdots \pi$ interactions.

The Hirshfeld surface [15] [16] provides a remarkable way of exploring intermolecular interactions in molecular crystals using a partitioning of crystal space in a novel visual manner. The surfaces encode information about all intermolecular interactions and offer a facile way of obtaining information on crystal packing. The breakdown of the associated fingerprint plots [17] explores quantitatively the types of intermolecular contacts experienced by molecules and presents this information in a convenient color plot. This plot provides a useful means of revealing significant similarities and differences between related structures by analyzing the packing motifs. The size and shape of the Hirshfeld surface are intimately related to the chemical environment surrounding the molecule, making it ideal for use in comparing different crystal structures incorporating the same molecule. In the context of crystal structure prediction, Hirshfeld surface base tools shows a major advance in analyzing intermolecular interactions [18] [19] and should be considered by the crystal engineers in building molecular architectures. The Hirshfeld surface and associated fingerprint plots of the three compounds have been presented to explore the nature of intermolecular interactions and their relative contributions in building the solid-state architecture. In addition, the thermal stability of the compounds has been investigated associated with the noncovalent interactions observed in the crystal structures.

\section{Experimental Section}

\subsection{Materials and Physical Measurements}

Nitrofurantoin, were obtained from Alfa Aesar corporation, $\mathrm{ZnCl}_{2}, 2,2$ '-dipyridyl and 1,10-phenanthroline were obtained from Sinopharm Chemical Reagent corporation, all available chemicals were of reagent grade and used without further purification. Elemental analyses were performed on a Thermo 1112 elemental analyzer. Infrared spectra were recorded on a Bruker-Tensor 27 FT-IR spectrometer with the samples prepared as KBr pellets. Thermogrvimetric analyses were performed using a SDT Q600 V8.3 Build101 thermal analyzer at a heating rate of $10^{\circ} \mathrm{C} / \mathrm{min}$ under an atmosphere of $\mathrm{N}_{2}$.

\subsection{Synthesis of Compounds}

$\mathrm{C}_{8} \mathrm{H}_{6} \mathrm{~N}_{4} \mathrm{O}_{5}$, (1). Nitrofurantoin ( $\beta$-form, $0.1 \mathrm{mmol}, 23.8 \mathrm{mg}$ ) and $\mathrm{ZnCl}_{2}(0.1 \mathrm{mmol}, 13.6 \mathrm{mg}$ ) were dissolved in $20 \mathrm{~mL} \mathrm{MeOH}$, and stirred about $20 \mathrm{~min}$, followed by slow cooling and evaporation. Yellow needles of 1 were formed after one week (yield 70\%). Elemental analysis. Anal. Calcd. (\%): C, 40.34; H, 2.54; N, 23.52. Found: C, 40.29; H, 2.55; N, 23.54. IR (KBr, cm $\left.{ }^{-1}\right)$ : 3289 s, 3147 m, 3017 w, 2925 w, 2859 w, 1781 m, 1742 s, 1656 w, $1610 \mathrm{w}, 1564 \mathrm{~s}, 1521 \mathrm{~s}, 1345 \mathrm{~s}, 1432 \mathrm{~s}, 1384.6 \mathrm{~m}, 1246 \mathrm{~s}, 1208 \mathrm{~m}, 1116 \mathrm{~s}$.

$\mathrm{C}_{8} \mathrm{H}_{6} \mathrm{~N}_{4} \mathrm{O}_{5} \cdot 0.5\left(\mathrm{C}_{10} \mathrm{H}_{8} \mathrm{~N}_{2}\right)$, (2). Nitrofurantoin (0.1 mmol, $\left.23.8 \mathrm{mg}\right)$ and 2,2'-dipyridyl (0.1 mmol, $\left.15.6 \mathrm{mg}\right)$ were dissolved in $15 \mathrm{~mL} \mathrm{MeCN}$, and stirred about $15 \mathrm{~min}$, followed by slow cooling and evaporation. Red block-like crystals of 2 were obtained after one day (90\%). Elemental analysis. Anal. Calcd. (\%): C, 49.37; H, 3.19; N, 22.14. Found: C, 49.40; H, 3.16; N, 22.12. IR (KBr, cm $\left.{ }^{-1}\right)$ : 3162 m, 3101 m, 3019 m, 2923 m, 2855 w, 1790 m, 1741 s, 1656 w, 1615 w,1564 w, 1521 s, 1346 s, 1431 s, 1383 s, 1254 s, 1208 m, 1123 s.

$\mathrm{C}_{8} \mathrm{H}_{6} \mathrm{~N}_{4} \mathrm{O}_{5} \cdot \mathrm{C}_{12} \mathrm{H}_{8} \mathrm{~N}_{2}$, (3). Nitrofurantoin $(0.1 \mathrm{mmol}, 23.8 \mathrm{mg})$ and 1,10-phenanthroline $(0.1 \mathrm{mmol}, 18.0 \mathrm{mg})$ were dissolved in $15 \mathrm{~mL} \mathrm{MeCN}$, and stirred about $15 \mathrm{~min}$, followed by slow cooling and evaporation. Olive block-like crystals of 3 were formed after two days (80\%). Elemental analysis. Anal. Calcd. (\%): C, 57.42; H, 3.37; N, 20.09. Found: C, 57.40; H, 3.39; N, 20.10. IR (KBr, cm $\left.{ }^{-1}\right)$ : 3144 w, 3058 m, 3008 s, 2925 m, 2861 m, 1781 m, 1735 s, 1648 w, 1614 w, 1556 w, 1508 s, 1350 s, 1424 s, 1381 s, 1255 s, 1209 m, 1101 s.

\subsection{X-Ray Crystallography}

Single crystal X-ray diffraction intensity data were collected using a Bruker SMART APEX CCD diffractometer equipped with graphite monochromated MoK $\alpha$ radiation $(\lambda=0.71073 \AA)$. The data reduction was carried out using the program Bruker SAINT [20] and corrected for absorption using SADABS [21]. The structures were solved by directed methods using SHELXTL [22] and refined by full matrix least-squares on $F^{2}$ with SHELXL- 
97 [23]. Data collection and refinement parameters for compounds 1-3 are summarized in Table 1.

\subsection{Hirshfeld Surfaces Analysis}

Molecular Hirshfeld surfaces and the associated fingerprint information of 1-3 were calculated using the Crystal Explorer 3.0 software [24]. All bond lengths to hydrogen were automatically modified to typical standard neutron values [25] $(\mathrm{C}-\mathrm{H}=1.083 \AA, \mathrm{N}-\mathrm{H}=1.009 \AA$ and $\mathrm{O}-\mathrm{H}=0.983 \AA)$, while the CIF. files of crystals 1-3 were read into the Crystal Explorer software program for calculations.

\section{Results and Discussion}

\subsection{Crystal Structures Description}

Compound 1 crystallizes in monoclinic space group $P 21 / c$ with $\beta=109.68^{\circ}$, which is one new polymorphism of nitrofurantoin [26] [27]. The structural parameters about the polymorphism reported including compound $\mathbf{1}$ are summarized in Table S1. The selected bond lengths and angles about NF molecule in compounds 1-3 are listed in Table 2, and perspective views of the structures for compounds 1-3 are shown in Figure 1. The bond lengths

Table 1. Crystallographic data for compounds 1-3.

\begin{tabular}{|c|c|c|c|}
\hline Compound & 1 & 2 & 3 \\
\hline Empirical formula & $\mathrm{C}_{8} \mathrm{H}_{6} \mathrm{~N}_{4} \mathrm{O}_{5}$ & $\mathrm{C}_{8} \mathrm{H}_{6} \mathrm{~N}_{4} \mathrm{O}_{5} \cdot 0.5\left(\mathrm{C}_{10} \mathrm{H}_{8} \mathrm{~N}_{2}\right)$ & $\mathrm{C}_{8} \mathrm{H}_{6} \mathrm{~N}_{4} \mathrm{O}_{5} \cdot \mathrm{C}_{12} \mathrm{H}_{8} \mathrm{~N}_{2}$ \\
\hline Formula weight & 238.17 & 316.26 & 418.37 \\
\hline Crystal system & Monoclinic & Monoclinic & Triclinic \\
\hline Crystal size/mm & $0.40 \times 0.25 \times 0.20$ & $0.42 \times 0.38 \times 0.35$ & $0.32 \times 0.28 \times 0.26$ \\
\hline Crystal color & Yellow & Red & Green \\
\hline Space group & $P 21 / \mathrm{c}$ & $P 21 / \mathrm{c}$ & $P-1$ \\
\hline $\mathrm{a} / \AA \AA$ & $7.849(3)$ & $6.6135(4)$ & $5.4793(4)$ \\
\hline $\mathrm{b} / \AA$ & $6.500(3)$ & $13.7714(9)$ & $10.9784(7)$ \\
\hline $\mathrm{c} / \AA \AA$ & 20.057 (7) & $14.4655(9)$ & $15.0993(10)$ \\
\hline$\alpha /^{\circ}$ & 90.00 & 90.00 & $97.5680(10)$ \\
\hline$\beta /^{\circ}$ & $109.68(1)$ & $100.1210(10)$ & $91.8940(10)$ \\
\hline$\gamma /^{\circ}$ & 90.00 & 90.00 & $93.1470(10)$ \\
\hline Volume $/ \AA^{3}$ & $963.5(7)$ & $1296.97(14)$ & $898.27(11)$ \\
\hline $\mathrm{Z}$ & 4 & 4 & 2 \\
\hline $\mathrm{Dc} / \mathrm{Mg} \cdot \mathrm{m}^{-3}$ & 1.642 & 1.620 & 1.547 \\
\hline$\mu / \mathrm{mm}^{-1}$ & 0.140 & 0.128 & 0.116 \\
\hline $\mathrm{F}(000)$ & 488 & 652 & 432 \\
\hline R (int) & 0.0310 & 0.0201 & 0.0267 \\
\hline Total data & 4535 & 11781 & 11937 \\
\hline Unique data & 1684 & 3250 & 4551 \\
\hline Goodness-of-fit on $\mathrm{F}^{2}$ & 1.199 & 1.041 & 1.041 \\
\hline$R_{1}^{a}, \mathrm{w} R_{2}^{b} \quad[\mathrm{I} \geq 2 \sigma(\mathrm{I})]$ & $0.0575,0.1113$ & $0.0340,0.0978$ & $0.0396,0.1179$ \\
\hline$R_{1}^{a}, \mathrm{w} R_{2}^{b} \quad$ (all data) & $0.0610,0.1128$ & $0.0359,0.0995$ & $0.0437,0.1220$ \\
\hline Largest diff. peak, hole/e $\AA^{-3}$ & $0.192,-0.193$ & $0.387,-0.255$ & $0.388,-0.269$ \\
\hline
\end{tabular}

${ }^{a} R_{1}=\sum|| F_{\mathrm{o}}|-| F_{\mathrm{c}}\left|/ \sum\right| F_{\mathrm{o}} \mid, \quad{ }^{b} \mathrm{w} R_{2}=\left\{\sum\left[\mathrm{w}\left(F_{\mathrm{o}}^{2}-F_{\mathrm{c}}^{2}\right)^{2}\right] / \sum\left[\mathrm{w}\left(F_{\mathrm{o}}^{2}\right)^{2}\right]\right\}^{1 / 2}$. 
Table 2. Selected bond lengths $(\AA)$ and angles $\left({ }^{\circ}\right)$ of compounds 1-3.

\begin{tabular}{|c|c|c|c|c|c|c|c|}
\hline Compound & 1 & 2 & 3 & & 1 & 2 & 3 \\
\hline C1-C3 & 1.507 (4) & $1.520(1)$ & $1.512(1)$ & C4-C5 & $1.440(4)$ & $1.439(1)$ & $1.438(2)$ \\
\hline C5-C6 & $1.352(4)$ & $1.368(1)$ & $1.368(2)$ & C6-C7 & $1.401(4)$ & $1.419(1)$ & $1.408(2)$ \\
\hline C7-C8 & 1.335 (4) & $1.356(1)$ & $1.357(2)$ & N1-C1 & $1.351(4)$ & $1.371(1)$ & $1.367(1)$ \\
\hline N1-C2 & 1.391 (3) & $1.397(1)$ & $1.396(1)$ & N2-C2 & $1.374(3)$ & $1.380(1)$ & $1.382(1)$ \\
\hline N2-C3 & 1.454 (3) & $1.452(1)$ & $1.449(1)$ & N3-C4 & $1.276(3)$ & $1.286(1)$ & $1.287(2)$ \\
\hline N2-N3 & 1.367 (3) & 1.359 (1) & $1.361(1)$ & N4-C8 & $1.416(3)$ & $1.426(1)$ & $1.414(1)$ \\
\hline O1-C1 & 1.205 (3) & $1.212(1)$ & $1.214(1)$ & O2-C2 & 1.196 (3) & $1.207(1)$ & 1.205 (1) \\
\hline O3-C5 & 1.369 (3) & $1.375(1)$ & $1.368(1)$ & O3-C8 & 1.357 (3) & $1.356(1)$ & $1.357(1)$ \\
\hline O4-N4 & 1.219 (3) & $1.227(1)$ & 1.229 (1) & O5-N4 & 1.224 (3) & $1.235(1)$ & $1.236(1)$ \\
\hline C1-N1-C2 & $113.7(2)$ & $112.60(8)$ & $112.48(9)$ & C2-N2-C3 & $113.4(2)$ & 112.76 (8) & $112.49(9)$ \\
\hline C4-N3-N2 & $117.2(2)$ & $115.93(9)$ & $114.93(9)$ & C5-C6-C7 & $107.2(2)$ & 106.65 (9) & $107.20(1)$ \\
\hline C6-C5-O3 & $110.5(2)$ & 110.73 (9) & $110.61(1)$ & C6-C5-C4 & $132.5(3)$ & 130.15 (9) & $128.53(1)$ \\
\hline C7-C8-N4 & $131.7(2)$ & 130.93 (9) & $129.84(1)$ & C7-C8-O3 & $113.0(2)$ & $113.11(9)$ & $113.29(1)$ \\
\hline C8-O3-C5 & $104.1(2)$ & 104.58 (8) & $104.40(8)$ & C8-C7-C6 & $105.2(2)$ & $104.93(9)$ & $104.50(1)$ \\
\hline N1-C1-C3 & $107.3(2)$ & $107.03(8)$ & 107.20 (9) & N2-C2-N1 & $104.6(2)$ & $105.94(9)$ & 105.89 \\
\hline N2-C3-C1 & $100.9(2)$ & 101.64 (8) & 101.84 (8) & N3-N2-C2 & $119.2(2)$ & 119.94 (8) & 121.11 \\
\hline N3-N2-C3 & $127.1(2)$ & 127.18 (8) & 126.36 (9) & N3-C4-C5 & $119.4(2)$ & 120.44 (9) & 122.20 \\
\hline O1-C1-C3 & $126.2(3)$ & 126.33 (9) & 125.55 (1) & O1-C1-N1 & $126.5(3)$ & $126.64(1)$ & $127.24(1)$ \\
\hline O2-C2-N1 & $126.8(2)$ & $126.43(1)$ & $126.74(1)$ & O2-C2-N3 & $128.6(2)$ & $127.64(1)$ & $127.36(1)$ \\
\hline O3-C5-C4 & $116.9(2)$ & $119.11(9)$ & 120.86 (1) & O3-C8-N4 & $115.3(2)$ & 115.95 (9) & $116.87(9)$ \\
\hline O4-N4-O5 & $124.6(2)$ & $124.73(9)$ & $124.60(1)$ & O4-N4-C8 & $119.1(2)$ & $118.77(9)$ & $119.20(1)$ \\
\hline O5-N4-C8 & $116.3(2)$ & 116.50 (9) & $116.20(1)$ & & & & \\
\hline
\end{tabular}

(1)
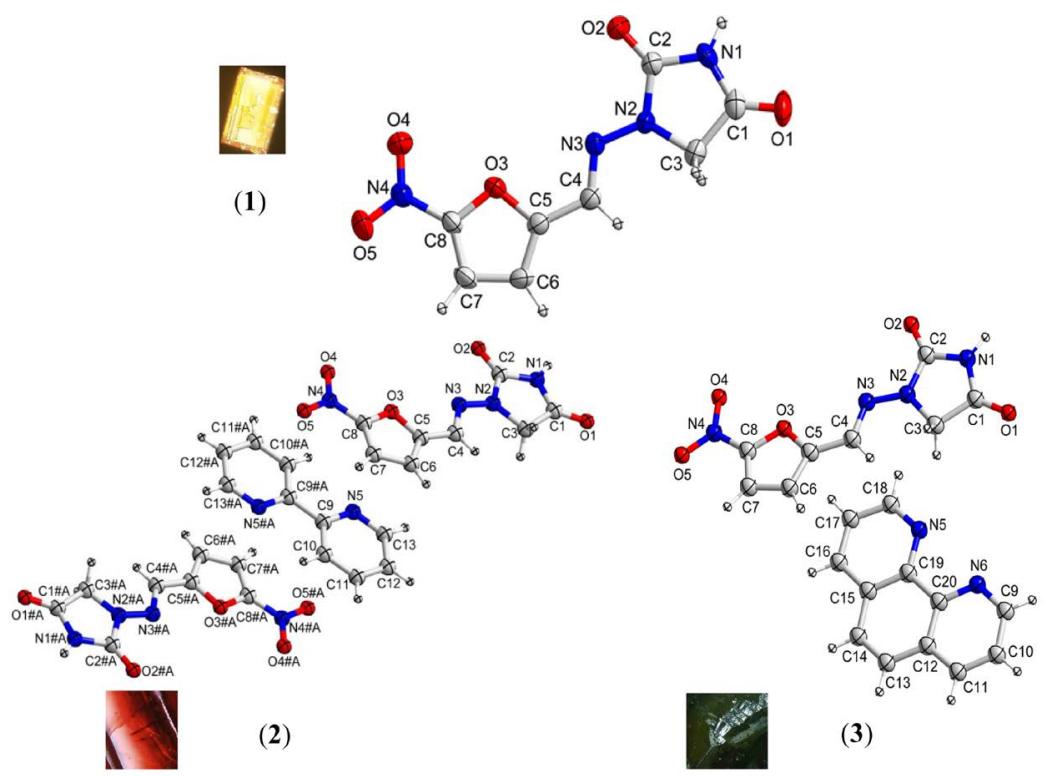

(3)

Figure 1. ORTEP views with atom numbering scheme of compounds 1-3. Thermal ellipsoids are shown at $50 \%$ probability level. Symmetry codes for the generated atoms: \#A $(-x+1,-y+1,-z+1)$. 
and angles of NF molecule in compounds 1-3 are similar, except that the lengths of the C-C bonds in furan ring and the N-O bonds of nitryl are slightly longer in compounds $\mathbf{2}$ and $\mathbf{3}$ than those in $\mathbf{1}$, which might attribute to the weak interactions between NF and bipy (or phen) molecules. As is illustrated in Table S2, the dihedral angle between the furan ring and the hydantoin ring in $\mathbf{3}$ is $10.98^{\circ}$, much larger than that in $\mathbf{1}\left(5.35^{\circ}\right)$ and $\mathbf{2}\left(3.26^{\circ}\right)$, due to the electron repulsion and steric hindrance of phen molecule in 3.

The crystal packing of compound 1 differs from the reported structures of NF [26] [27], stabilized by combination of $\mathrm{N}-\mathrm{H} \cdots \mathrm{O}$ and $\mathrm{C}-\mathrm{H} \cdots \mathrm{O}$ hydrogen bonds (Table 3). One imdazole nitrogen atom $\mathrm{N} 1(\mathrm{x}, \mathrm{y}, \mathrm{z})$ acts as donor to $\mathrm{O} 1$ atom at $(-\mathrm{x}+1, \mathrm{y}+1 / 2,-\mathrm{z}+1 / 2)$, along with C4-H4A $\cdots \mathrm{O} 2(\mathrm{x}, \mathrm{y}-1, \mathrm{z}), \mathrm{C} 7-\mathrm{H} 7 \mathrm{~A} \cdots \mathrm{O} 4(\mathrm{x}, \mathrm{y}-1, \mathrm{z})$, generating one dimensional parallel ribbon in $\mathbf{1}$. These hydrogen bonded motif can be described using the graph set notation as $R_{3}^{3}(15) R_{2}^{2}(16)$ (Figure 2).

In 2, one bipy and two NF molecules act as a synthon forming $1 \mathrm{D}$ chains with $\mathrm{ABB}$ type. One bipy molecule is linked to two NF molecule through H-bond interactions (Table 3), C10-H10A $\cdots \mathrm{O} 1(\mathrm{x}, \mathrm{y}+1, \mathrm{z})$, $\mathrm{C} 13-\mathrm{H} 13 \mathrm{~A} \cdots \mathrm{O} 2(-\mathrm{x}+1,-\mathrm{y},-\mathrm{z}+1)$ and N1-H1A $\cdots \mathrm{N} 5(-\mathrm{x}+1,-\mathrm{y},-\mathrm{z}+1)$, which give rise to the $R_{2}^{2}(9)$ and $R_{2}^{2}(7)$ cyclic motifs (Figure 3(a)). Between two NF molecules, there are two H-bond interactions (C7H7A $\cdots \mathrm{O} 5(-\mathrm{x},-\mathrm{y}+1,-\mathrm{z}+1))$, forming a $R_{2}^{2}(10)$ motif. The parallel chains stack through $\pi \cdots \pi$ and nitryl-O $\cdots \pi$ interactions (Table 4 and Table 5) with the average distance of $3.246 \AA$. The adjecent chains link with the above chain (angle: $\left.28.16^{\circ}\right)$ through hydrogen bond interactions, C6-H6A $\cdots \mathrm{O} 1(-\mathrm{x}+1, \mathrm{y}+1 / 2,-\mathrm{z}+$ 1/2) and C11-H11A $\cdots \mathrm{O} 2(\mathrm{x},-\mathrm{y}+1 / 2, \mathrm{z}-1 / 2)$, forming a 3D supramolecular network Figure 3(b) and Figure $3(c)$.

Table 3. Hydrogen bond parameters $\left(\AA,^{\circ}\right)$ for compounds 1-3.

\begin{tabular}{|c|c|c|c|c|c|c|}
\hline Compound & $\mathrm{D}-\mathrm{H} \cdots \mathrm{A}$ & D-H & $\mathrm{H} \cdots \mathrm{A}$ & $\mathrm{D} \cdots \mathrm{A}$ & $\mathrm{D}-\mathrm{H} \cdots \mathrm{A}$ & Sym. Code \\
\hline \multirow[t]{3}{*}{1} & $\mathrm{C} 4-\mathrm{H} 4 \mathrm{~A} \cdots \mathrm{O} 2$ & $0.91(3)$ & $2.49(3)$ & $3.400(4)$ & $178(2)$ & $\mathrm{x}, \mathrm{y}-1, \mathrm{z}$ \\
\hline & C7-H7A $\cdots$ O4 & 0.93 & 2.48 & $3.076(4)$ & 122 & $\mathrm{x}, \mathrm{y}-1, \mathrm{z}$ \\
\hline & N1-H1A $\cdots$ O1 & 0.86 & 2.01 & 2.819 (3) & 158 & $-x+1, y+1 / 2, z+1 / 2$ \\
\hline \multirow[t]{6}{*}{2} & C6-H6A $\cdots \mathrm{O} 1$ & 0.93 & 2.44 & $3.344(1)$ & 163 & $-x, y+1 / 2,-z+1 / 2$ \\
\hline & C7-H7A $\cdots$ O5 & 0.93 & 2.45 & $3.254(1)$ & 144 & $-\mathrm{x},-\mathrm{y}+1,-\mathrm{z}+1$ \\
\hline & $\mathrm{C} 10-\mathrm{H} 10 \mathrm{~A} \cdots \mathrm{O} 1$ & $0.95(2)$ & $2.45(2)$ & $3.283(1)$ & $146.8(1)$ & $\mathrm{x}, \mathrm{y}+1, \mathrm{z}$ \\
\hline & $\mathrm{C} 11-\mathrm{H} 11 \mathrm{~A} \cdots \mathrm{O} 2$ & 0.93 & 2.38 & $3.153(1)$ & 140 & $x,-y+1 / 2, z-1 / 2$ \\
\hline & $\mathrm{C} 13-\mathrm{H} 13 \mathrm{~A} \cdots \mathrm{O} 2$ & 0.93 & 2.50 & $3.361(1)$ & 154 & $-\mathrm{x}+1,-\mathrm{y},-\mathrm{z}+1$ \\
\hline & $\mathrm{N} 1-\mathrm{H} 1 \mathrm{~A} \cdots \mathrm{N} 5$ & 0.86 & 2.12 & $2.969(1)$ & 168 & $-\mathrm{x}+1,-\mathrm{y},-\mathrm{z}+1$ \\
\hline \multirow[t]{6}{*}{3} & С9-H9A $\cdots \mathrm{O} 2$ & 0.93 & 2.53 & $3.193(2)$ & 128 & $-\mathrm{x},-\mathrm{y}+1,-\mathrm{z}$ \\
\hline & C10-H10A $\cdots$ O2 & 0.93 & 2.37 & $3.261(2)$ & 161 & $x+1, y-1, z$ \\
\hline & C13-H13A $\cdots$ O4 & 0.93 & 2.55 & $3.425(2)$ & 157 & $x+1, y-1, z$ \\
\hline & C18-H18A $\cdots$ O1 & 0.93 & 2.40 & $3.122(1)$ & 134 & $-\mathrm{x},-\mathrm{y}+1,-\mathrm{z}$ \\
\hline & N1-H1A $\cdots$ N5 & 0.86 & 2.24 & $2.999(1)$ & 147 & $-\mathrm{x},-\mathrm{y}+1,-\mathrm{z}$ \\
\hline & $\mathrm{N} 1-\mathrm{H} 1 \mathrm{~A} \cdots \mathrm{N} 6$ & 0.86 & 2.41 & $3.128(1)$ & 142 & $-x,-y+1,-z$ \\
\hline
\end{tabular}

Table 4. Geometrical parameters $\left(\AA,{ }^{\circ}\right)$ for the $\pi \cdots \pi$ interactions for compounds $2-3^{a}$.

\begin{tabular}{cccccccc}
\hline Ring $(\mathrm{i}) \rightarrow \operatorname{Ring}(\mathrm{j})^{\mathrm{a}}$ & $\mathrm{Rc}^{\mathrm{b}}$ & ${\mathrm{R} 1 \mathrm{v}^{\mathrm{c}}}$ & ${\mathrm{R} 2 \mathrm{v}^{\mathrm{d}}}$ & $\alpha$ & $\beta$ & $\gamma$ & Sym. Code \\
\hline Compound 2 & & & & & & & \\
$\mathrm{Cg}(1) \cdots \operatorname{Cg}(2)$ & $3.9171(7)$ & $-3.3170(5)$ & $3.4209(4)$ & $3.05(6)$ & 29.15 & 32.13 & $\mathrm{x}, \mathrm{y}, \mathrm{z}$ \\
$\quad$ Compound 3 & & & & & & \\
$\operatorname{Cg}(3) \cdots \operatorname{Cg}(4)$ & $4.1113(7)$ & $3.3429(5)$ & $-3.3689(5)$ & $0.96(5)$ & 34.97 & 35.60 & $1-\mathrm{x}, \mathrm{y}, \mathrm{z}$ \\
\hline
\end{tabular}

${ }^{\mathrm{a}} \mathrm{Cg}(\mathrm{I})$ are the centroids of above rings, Ring1 = O3-C5-C6-C7-C8, Ring2 = N5-C9-C10-C11-C12-C13, Ring3 = N5-C18-C17-C16-C15-C19, Ring4 = C12-C13-C14-C15-C19-C20. ${ }^{\mathrm{b} C e n t r o i d ~ d i s t a n c e ~ b e t w e e n ~ r i n g ~ I ~ a n d ~ r i n g ~ J . ~ ' ~ P e r p e n d i c u l a r ~ d i s t a n c e ~ o f ~ r i n g ~ c e n t r o i d ~ I ~ o n ~ r i n g ~ J . ~}{ }^{\mathrm{d}}$ Perpendicular distance of ring centroid $\mathrm{J}$ on ring $\mathrm{I}$. 
Table 5. Geometrical parameters $\left(\AA,{ }^{\circ}\right)$ for the lone pair $\cdots \pi$ interactions for compounds $2-3^{\mathrm{a}}$.

\begin{tabular}{|c|c|c|c|c|c|}
\hline$Y-X(I) \cdots C g(j)^{a}$ & $\mathrm{X} \cdots \mathrm{C}(\mathrm{g})$ & $\mathrm{Y} \cdots \mathrm{C}(\mathrm{g})$ & $\mathrm{Y} \cdots \mathrm{X}-\mathrm{C}(\mathrm{g})$ & X-Perp & Sym. Code \\
\hline \multicolumn{6}{|l|}{ Compound 2} \\
\hline $\mathrm{N} 4-\mathrm{O} 5 \cdots \mathrm{Cg}(2)$ & $3.419(1)$ & $3.812(1)$ & 98.97 (6) & 3.355 & $1-x, 1-y, 1-z$ \\
\hline \multicolumn{6}{|l|}{ Compound 3} \\
\hline N4-O4 $\cdots \mathrm{Cg}(4)$ & $3.582(1)$ & 3.724 (1) & $86.92(7)$ & -3.526 & $x, y+1, z$ \\
\hline
\end{tabular}

${ }^{\mathrm{a}} \mathrm{Cg}(\mathrm{I})$ are the centroids of above rings, Ring2 = N5-C9-C10-C11-C12-C13, Ring4 = C12-C13-C14-C15-C19-C20.

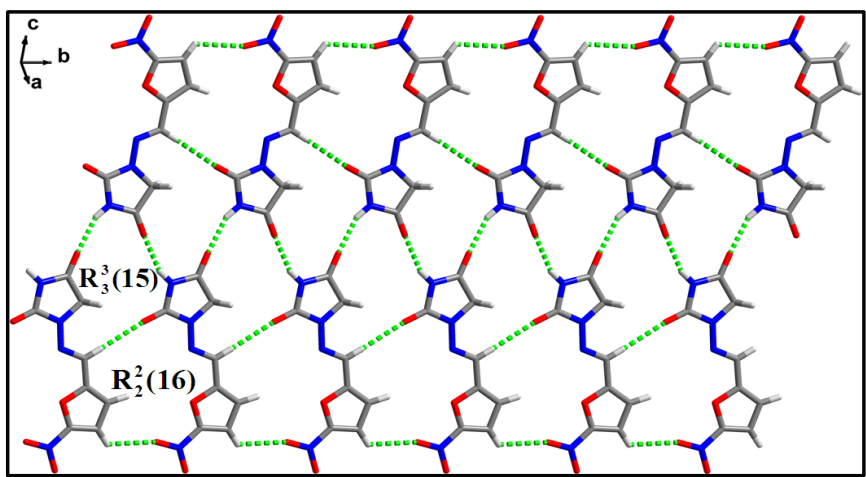

Figure 2. View of the 1D ribbon-like structure in $\mathbf{1}$ along the b-axis.

For 3, two NF and two phen molecules link with each other through $\mathrm{C}-\mathrm{H} \cdots \mathrm{O}$ and $\mathrm{N}-\mathrm{H} \cdots \mathrm{N}$ hydrogen bonds (Table 3), forming an isolated square-planar unit (Figure 4(a)), giving rise to the $R_{1}^{2}(5), R_{2}^{2}(7), R_{4}^{2}(10)$ and $R_{2}^{2}(16)$ motifs. The parallel planar units stack through $\pi \cdots \pi$ and nitryl-O $\cdots \pi$ interactions (Table 4 and Table 5), which are similar to those in compound 2, forming the 1D "square column" motifs (Figure 4(b)).

\subsection{Hirshfeld Surfaces Analysis}

Herein, the Hirshfeld surfaces of compounds 1-3 are illustrated in Figure 5, showing the surfaces that have been mapped over $d_{\text {norm }}$ and shape-index. The information given in Table 3 is summarized effectively in the Hirshfeld surfaces as the large circular red areas marked with $\mathrm{N} \cdots \mathrm{H}$ and $\mathrm{O} \cdots \mathrm{H}$, respectively. The other small extents of visible red spots and light-white regions in the $d_{\text {norm }}$ surfaces are indicative of weaker and longer contacts other than hydrogen bonds (Figure $5, d_{n o r m}$ ). The hydrogen bonds interactions are also evident in shape-index by a red concave region around the acceptor atom and a complementary blue convex region around the hydrogen bond donor. Apart from hydrogen bonds, the $\pi \cdots \pi$ interactions stacks for 2-3 are also observed on the same region of the shape index as the pattern of red and blue triangles highlighted by black dashed circles (Figure 5, right).

Meanwhile, the 2D fingerprint plots that decomposed to highlight particular atoms pair close contacts are provided in Figure 6, and the relative contributions of individual intermolecular interactions to the Hirshfeld surfaces area are depicted in Figure 7. In 1, the $\mathrm{O} \cdots \mathrm{H} / \mathrm{H} \cdots \mathrm{O}$ intermolecular interactions appear as a pair of symmetrical large sharp spikes in the fingerprint plots in the region of (1.10 $\AA, 0.76 \AA$ ), which comprise $50.4 \%$ of the total Hirshfeld surfaces area. The $\mathrm{N} \cdots \mathrm{H} / \mathrm{H} \cdots \mathrm{N}$ interactions comprise $3.9 \%$ of the total Hirshfeld surfaces and represent two small wings with $d_{\mathrm{i}}+d_{\mathrm{e}}=3.08 \AA$, which is longer than the $r^{v d W}$ separation and suggests the absence of any $\mathrm{C} / \mathrm{N}-\mathrm{H} \cdots \mathrm{N}$. Furthermore, the $\mathrm{H} \cdots \mathrm{H}$ interactions are displayed in the distribution of scattered points in the fingerprint plots, which spread up to $d_{\mathrm{i}}=d_{\mathrm{e}}=1.39 \AA$ and comprise $10.0 \%$ of the total Hirshfeld surfaces. Unlike 1, the $\mathrm{O} \cdots \mathrm{H} / \mathrm{H} \cdots \mathrm{O}$ intermolecular interactions are longer in $\mathbf{2}\left(d_{\mathrm{i}}+d_{\mathrm{e}}=2.27 \AA\right)$ and $\mathbf{3}\left(d_{\mathrm{i}}+d_{\mathrm{e}}=\right.$ $2.24 \AA$ ), respectively, with the smaller percentage of $45.6 \%$ and $36.1 \%$ to the total Hirshfeld surfaces, respectively. However, the $\mathrm{N} \cdots \mathrm{H} / \mathrm{H} \cdots \mathrm{N}$ interactions are displayed in two sharp spikes in the fingerprint plots, which spread up to the shorter distance of $d_{\mathrm{i}}+d_{\mathrm{e}}=1.98 \AA$ and $d_{\mathrm{i}}+d_{\mathrm{e}}=2.16 \AA$ for 2 and 3, respectively, and contribute $8.7 \%$ and $13.2 \%$ to the total Hirshfeld surfaces, respectively. The $\mathrm{H} \cdots \mathrm{H}$ interactions have more significant contribution to the total Hirshfeld surfaces in 2 (20.2\%) and $\mathbf{3}$ (20.7\%) when compared with $\mathbf{1}$, which spread up to 


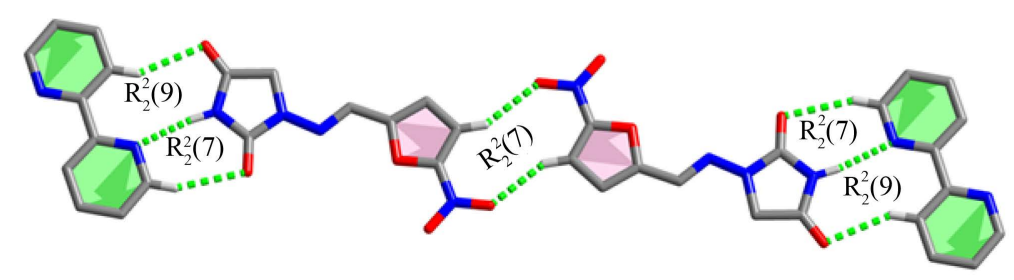

(a)

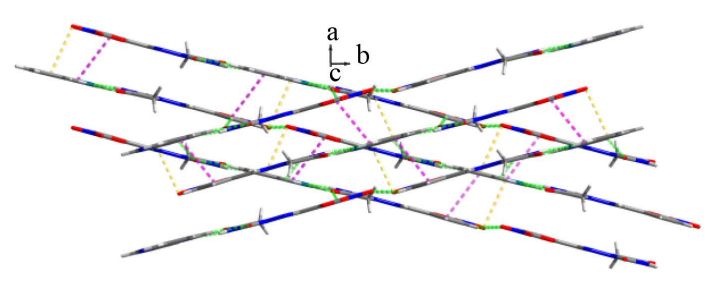

(b)

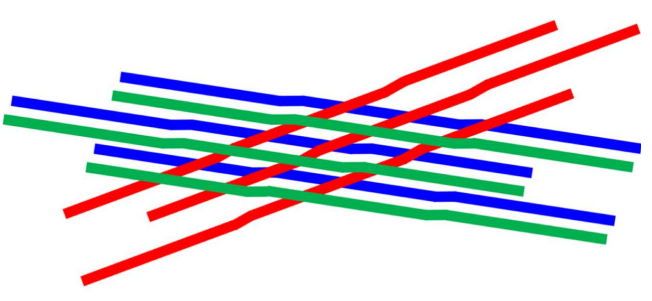

(c)

Figure 3. (a) View of the hydrogen bond interactions in 2; (b) The 3D grid-like supramolecular structure viewed down the c-axis in 2; (c) A diagrammatic representation of the 3D supramolecular architecture.

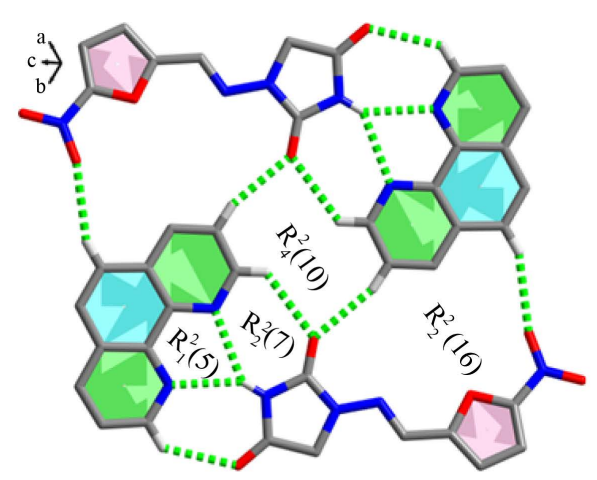

(a)

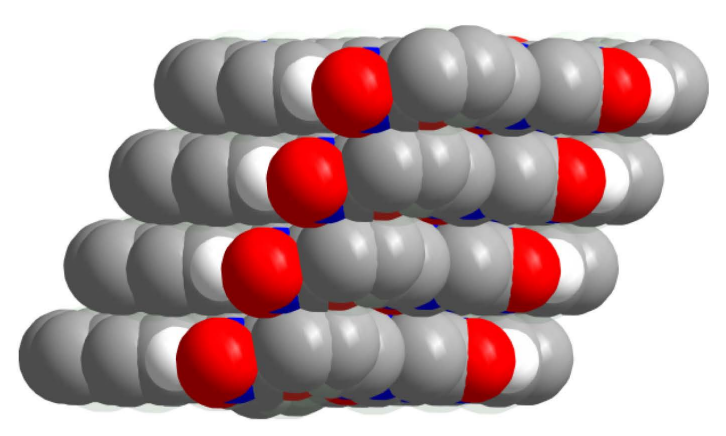

(b)

Figure 4. (a) View of the hydrogen bond interactions in 3; (b) A space-filling model of 1D structure in 3.

$d_{\mathrm{i}}=d_{\mathrm{e}}=1.08 \AA$ and $d_{\mathrm{i}}=d_{\mathrm{e}}=0.9 \AA$, respectively. The most significant difference amongst 1-3 is the presence of $\pi \cdots \pi /$ lone pair stacking interactions only in 2 and $\mathbf{3}$, while introduce the Bipy and Phen molecules. The $\pi \cdots \pi$ stacking interactions is closer in $\mathbf{3}\left(d_{\mathrm{i}}+d_{\mathrm{e}}=3.16 \AA\right)$ than in $\mathbf{2}\left(d_{\mathrm{i}}+d_{\mathrm{e}}=3.28 \AA\right)$, and the proportions of the total Hirshfeld surfaces are $4.0 \%$ and $2.4 \%$, respectively. The $\mathrm{O} \cdots \mathrm{C} / \mathrm{C} \cdots \mathrm{O}$ contacts associated with lone pair $\cdots \pi$ stacking interactions are closer and maximum in $\mathbf{3}\left(d_{i}+d_{e}=3.08 \AA, 7.0 \%\right)$ than that in $\mathbf{2}\left(d_{\mathrm{i}}+d_{\mathrm{e}}=3.14 \AA\right.$, $4.7 \%)$, respectively.

\subsection{Thermal Analysis}

The thermal behaviors of compounds 1-3 have been investigated, and the TGA curves are shown in Figure 8. In compound 1, the NF molecule decomposed at $230^{\circ} \mathrm{C}$ with the weight loss of $46.2 \%$ (calc. $47.4 \%$ ), which is slightly lower than that of $\beta$-NF $\left(240^{\circ} \mathrm{C}\right)$ [28]. For compound 2, the bipy molecule decomposed before the NF molecule at about $154.0^{\circ} \mathrm{C}$ with the weight loss of $25.1 \%$, which is in a good agreement with the calculated value of $24.7 \%$. While to compound 3 , the NF molecule decomposed before the phen molecule at $175^{\circ} \mathrm{C}$ with the weight loss of $26.2 \%$ (calc. $27.0 \%$ ).

\section{Conclusion}

In summary, the crystal structures, Hirshfeld surfaces and thermal behaviors of the title compounds 1-3 are studied. 
(1)
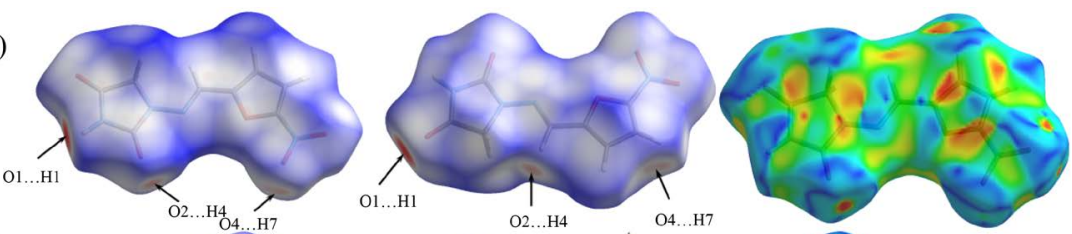

(2)
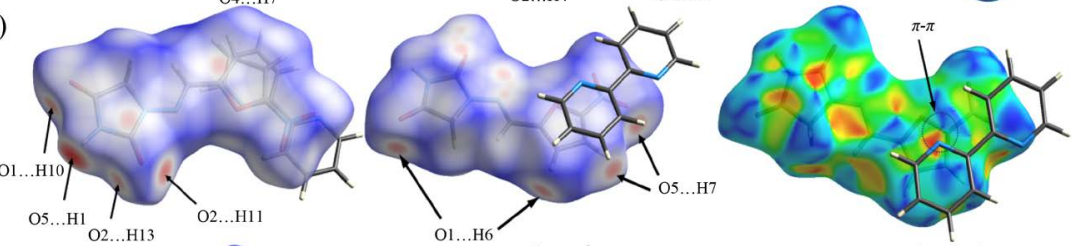

(3)
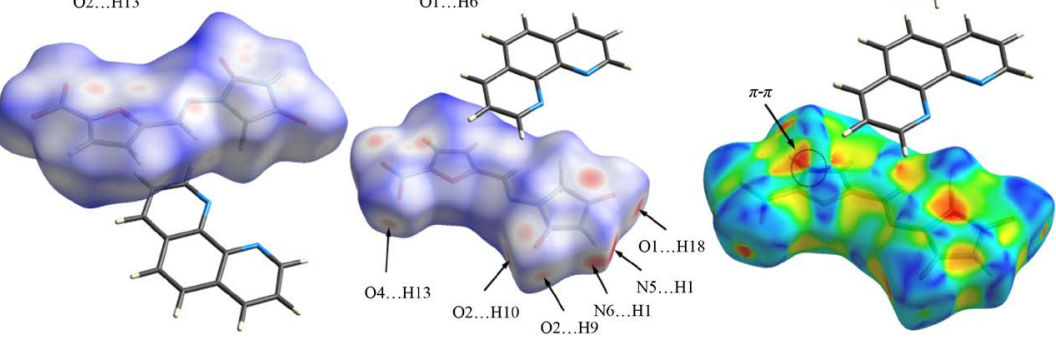

Figure 5. Hirshfeld surfaces mapped with $d_{\text {norm }}$ (front view, left), $d_{\text {norm }}$ (back view, middle) and shape index (right) of NF in compounds 1-3, respectively. The $\pi \cdots \pi$ stacking interactions are highlighted by black dashed circles.
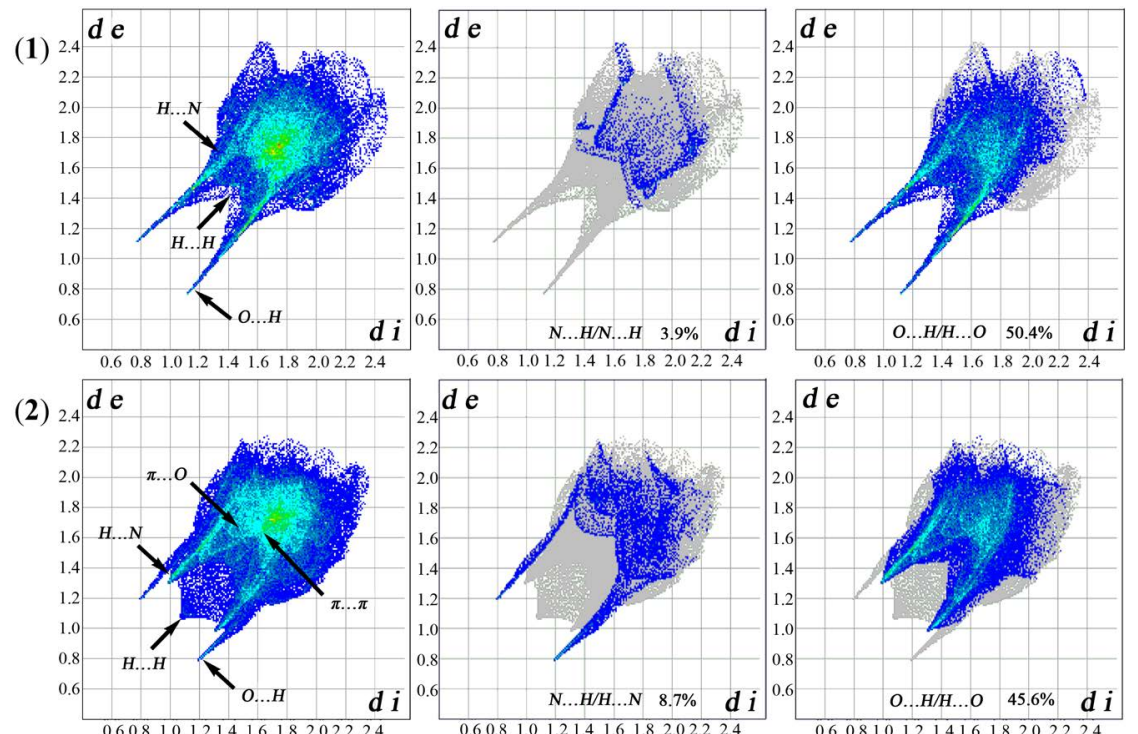

(3)
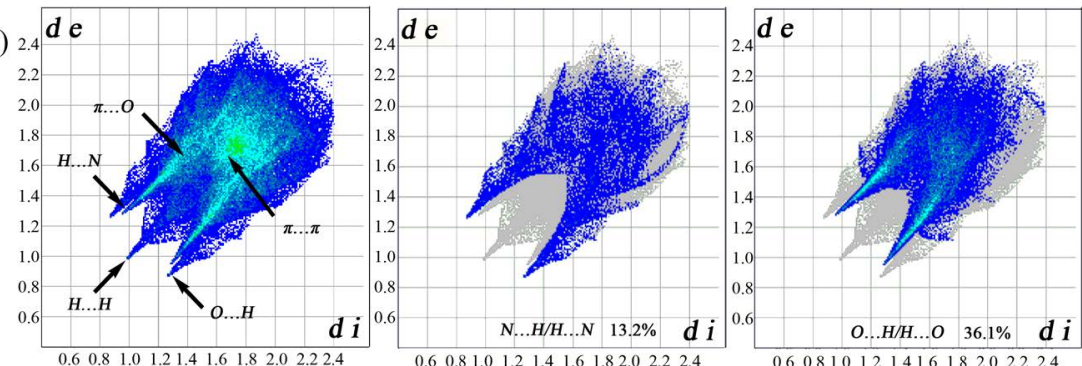

Figure 6. Fingerprint plots of compounds 1-3: Full (left) and resolved into $\mathrm{N} \cdots \mathrm{H} / \mathrm{H} \cdots \mathrm{N}$ (middle) and $\mathrm{O} \cdots \mathrm{H} / \mathrm{H} \cdots \mathrm{O}$ (right) contacts, showing the percentages of contacts contributed to the total Hirshfeld surface area of molecules. 


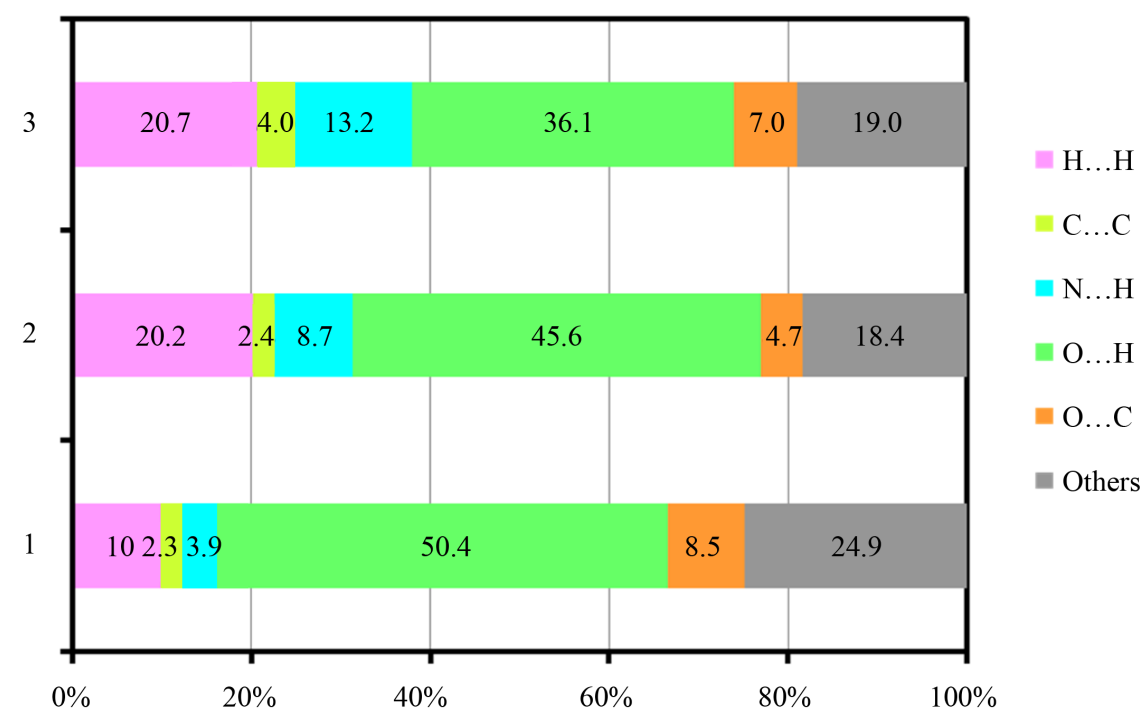

Figure 7. Relative contributions of various intermolecular contacts to the Hirshfeld surfaces area in compounds $\mathbf{1 - 3 .}$

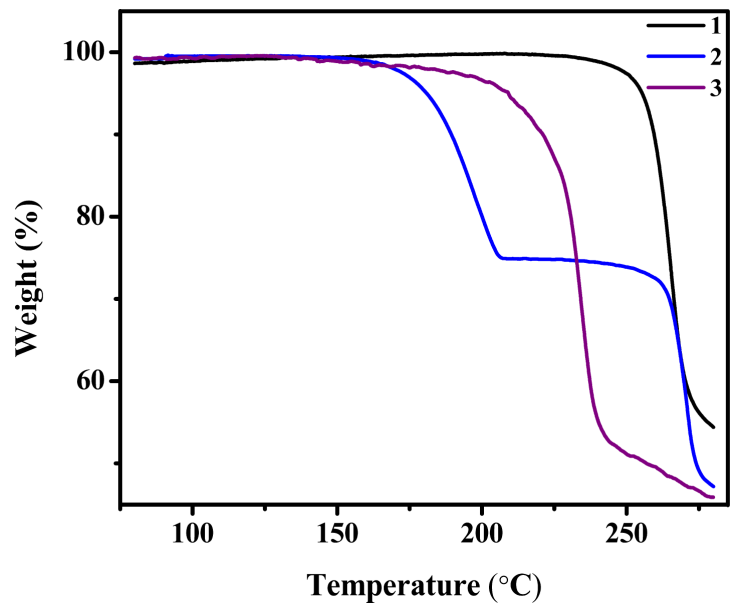

Figure 8. TGA curves for $\mathbf{1}$ (black), 2 (blue), and $\mathbf{3}$ (violet).

With the construction of hydrogen bond interaction, along with $\pi \cdots \pi /$ lone pair stacking interactions (for 2 and 3 ), the supramolecular structures are formed, $1 \mathrm{D}$ parallel ribbon structure of $\mathbf{1}$, 3D grid network of 2 , and $1 \mathrm{D}$ square column of 3 . The Hirshfeld surfaces and 2D fingerprint plots analyses make the understanding of the intermolecular interactions easily. In addition, the thermal stable studies show that the intermolecular interactions play a key role in the thermal properties of the compounds.

\section{Acknowledgements}

This work was supported by the National Natural Science Foundation of China (20971101 and 21271142) and the Master Innovation Foundation of Wenzhou University (3160603601011344).

\section{References}

[1] Seth, S.K., Manna, P., Singh, N.J., Mitra, M., Jana, A.D., Das, A., Choudhury, S.R., Kar, T., Mukhopadhyay, S. and Kim, K.S. (2013) Molecular Architecture Using Novel Types of Non-Covalent $\pi$-Interactions Involving Aromatic Neutrals, Aromatic Cations and $\pi$-Anions. CrystEngComm, 15, 1285-1288. http://dx.doi.org/10.1039/c2ce26577j

[2] Boer, S.A., Hawes, C.S. and Turner, D.R. (2014) Engineering Entanglement: Controlling the Formation of Polycate- 
nanes and Polyrotaxanes Using $\pi$-Interactions. Chemical Communications, 50, 1125-1127. http://dx.doi.org/10.1039/c3cc48802k

[3] Brancatelli, G., Pappalardo, S., Gattuso, G., Notti, A., Pisagatti, I., Parisi, M.F. and Geremia, S. (2014) Hydrogen Bond-Assisted Solid-State Formation of a Salt-Bridged Calix[5] Arene Pseudo-Dimer. CrystEngComm, 16, 89-93. http://dx.doi.org/10.1039/C3CE41667D

[4] Nishio, M., Umezawa, Y., Fantini, J., Weiss, M.S. and Chakrabarti, P. (2014) CH- $\pi$ Hydrogen Bonds in Biological Macromolecules. Physical Chemistry Chemical Physics, 16, 12648-12683. http://dx.doi.org/10.1039/c4cp00099d

[5] Black, H.T. and Perepichka, D.F. (2014) Crystal Engineering of Dual Channel p/n OrganicSemiconductors by Complementary Hydrogen Bonding. Angewandte Chemie, 126, 2170-2174. http://dx.doi.org/10.1002/ange.201310902

[6] Kadam, R.U., Garg, D., Schwartz, J., Visini, R., Sattler, M., Stocker, A., Darbre, T. and Reymond, J.L. (2013) CH- $\pi$ "T-Shape” Interaction with Histidine Explains Binding of Aromatic Galactosides to Pseudomonas aeruginosa Lectin LecA. ACS Chemical Biology, 8, 1925-1930.

[7] Takahashi, O., Kohno, Y. and Nishio, M. (2010) Relevance of Weak Hydrogen Bonds in the Conformation of Organic Compounds and Bioconjugates: Evidence from Recent Experimental Data and High-Level ab Initio MO Calculations. Chemical Reviews, 110, 6049-6076. http://dx.doi.org/10.1021/cr100072x

[8] Pienaar, E.W., Caira, M.R. and Lötter, A.P. (1993) Polymorphs of Nitrofurantoin. I. Preparation and X-Raycrystal Structures of Two Monohydrated Forms of Nitrofurantoin. Journal of Crystallographic and Spectroscopic Research, 23, 739-744. http://dx.doi.org/10.1007/BF01187276

[9] Ertan, G., Karasulu, Y. and Güneri, T. (1993) Degradation and Gastrointestinal Stability of Nitrofurantoin in Acidic and Alkaline Media. International Journal of Pharmaceutics, 96, 243-248. http://dx.doi.org/10.1016/0378-5173(93)90233-6

[10] Cherukuvada, S., Babu, N.J. and Nangia, A. (2011) Nitrofurantoin-p-Aminobenzoic Acid Cocrystal: Hydration Stability and Dissolution Rate Studies. Journal of Pharmaceutical Sciences, 100, 3233-3244. http://dx.doi.org/10.1002/jps.22546

[11] Tutughamiarso, M., Bolte, M., Wagner, G. and Egert, E. (2011) Five Pseudopolymorphs and a Cocrystal of Nitrofurantoin. Acta Crystallographica Section C, 67, o18-o25.

[12] Vangala, V.R., Chow, P.S. and Tan, R.B.H. (2012) Co-Crystals and Co-Crystal Hydrates of the Antibiotic Nitrofurantoin: Structural Studies and Physicochemical Properties. Crystal Growth \& Design, 12, 5925-5938. http://dx.doi.org/10.1021/cg300887p

[13] Vangala, V.R., Chow, P.S. and Tan, R.B.H. (2013) The Solvates and Salt of Antibiotic Agent, Nitrofurantoin: Structural, Thermochemical and Desolvation Studies. CrystEngComm, 15, 878-889. http://dx.doi.org/10.1039/C2CE26575C

[14] Babu, N.J., Cherukuvada, S., Thakuria, R. and Nangia,A. (2010) Conformational and Synthon Polymorphism in Furosemide (Lasix). Crystal Growth \& Design, 10, 1979-1989. http://dx.doi.org/10.1021/cg100098z

[15] McKinnon, J.J., Spackman, M.A. and Mitchell, A.S. (2004) Novel Tools for Visualizing and Exploring Intermolecular Interactions in Molecular Crystals. Acta Crystallographica Section B, 60, 627-668.

[16] Spackman, M.A. and Jayatilaka, D. (2009) Hirshfeld Surface Analysis. CrystEngComm, 11, 19-32. http://dx.doi.org/10.1039/B818330A

[17] McKinnon, J.J., Jayatilaka, D. and Spackman, M.A. (2007) Towards Quantitative Analysis of Intermolecular Interactions with Hirshfeld Surfaces. Chemical Communications, No. 37, 3814-3816. http://dx.doi.org/10.1039/b704980c

[18] Manna, P., Seth, S.K., Das, A., Hemming, J., Prendergast, R., Helliwell, M., Choudhury, S.R., Frontera, A. and Mukhopadhyay, S. (2012) Anion Induced Formation of Supramolecular Associations Involving Lone Pair- $\pi$ and Anion- $\pi$ Interactions in Co(II) Malonate Complexes: Experimental Observations, Hirshfeld Surface Analyses and DFT Studies. Inorganic Chemistry, 51, 3557-3571. http://dx.doi.org/10.1021/ic202317f

[19] Luo, Y.H., Wu, D.E., Song, W.T., Ge, S.W. and Sun, B.W. (2014) Positions of Amino Groups on Ammonium Salts Tunes the Conformations of Crown Ethers: Crystal Structures, Hirshfeld Surfaces and Spectroscopic Studies. CrystEngComm, 16, 5319-5330. http://dx.doi.org/10.1039/c4ce00150h

[20] Sheldrick, G.M. (2004) APEX-II, SAINT-Plus and TWINABS. Bruker-Nonius AXS Inc., Madison.

[21] Sheldrick, G.M. (2002) SAINT (Version 6.02), SADABS (Version 2.03). Bruker AXS Inc., Madison.

[22] Sheldrick, G.M. (2002) SHELXTL (Version 6.10). Bruker AXS Inc., Madison.

[23] Sheldrick, G.M. (1997) SHELXL-97, Program for X-ray Crystal Structure Solution and Refinement. University of Göttingen, Göttingen.

[24] Wolff, S.K., Grimwood, D.J., McKinnon, J.J., Turner, M.J., Jayatilaka, D. and Spackman, M.A. (2012) Crystal Explorer 3.0. University of Western Australia, Perth. 
[25] Allen, F.H., Kennard, O., Watson, D.G., Brammer, L., Orpen, A.G. and Taylor, R. (1987)Tables of Bond Lengths determined by X-Ray and Neutron Diffraction. Part 1. Bond Lengths in Organic Compounds. Journal of the Chemical Society, Perkin Transactions, 2, S1-S19. http://dx.doi.org/10.1039/p298700000s1

[26] Bertolasi, V., Gilli, P., Ferretti, V. and Gilli, G. (1993) Structure and Crystal Packing of the Antibacterial Drug 1-\{[(5Nitro-2-Furanyl)Methylene]Amino\}-2,4-Imidazolidinedione (Nitrofurantoin). Acta Crystallographica Section C, 49, 741-744. http://dx.doi.org/10.1039/p298700000s1

[27] Pienaar, E.W., Caira, M.R. and Lötter, A.P. (1993) Polymorphs of Nitrofurantoin. 2. Preparation and X-Ray Crystal Structures of Two Anhydrous Forms of Nitrofurantoin. Journal of Crystallographic and Spectroscopic Research, 23, 785-790. http://dx.doi.org/10.1007/BF01247241

[28] Vangala, V.R., Chow, P.S. and Tan, R.B.H. (2011) Characterization, Physicochemical and Photo-Stability of a CoCrystal Involving an Antibiotic Drug, Nitrofurantoin, and 4-Hydroxybenzoic Acid. CrystEngComm, 13, 759-762. http://dx.doi.org/10.1039/C0CE00772B

\section{Supplementary Material}

Table S1 listing unit cell parameters of nitrofurantoin crystal structures reported in the CSD and in this study. Table S2 listing the dihedral angle between the furan and the hydantoin ring designated by $\alpha$. Crystallographic data (excluding structure factors) for compounds 1-3 have been deposited with the Cambridge Crystallographic Data Centre (CCDC) as supplementary publication numbers CCDC 1035025, 1035026 and 1035027, respectively. Copies of the data can be obtained on application to CCDC, 12 Union Road, Cambridge CB2 1EZ, UK [Fax: +441223336033; e-mail:deposit@ccdc.cam.ac.uk.

Table S1. Unit cell parameters of Nitrofurantoin crystal structures reported in the CSD and in this study.

\begin{tabular}{|c|c|c|c|c|}
\hline Compound & NF-1 & NF-2 & NF-3 & 1 \\
\hline Empirical formula & $\mathrm{C}_{8} \mathrm{H}_{6} \mathrm{~N}_{4} \mathrm{O}_{5}$ & $\mathrm{C}_{8} \mathrm{H}_{6} \mathrm{~N}_{4} \mathrm{O}_{5}$ & $\mathrm{C}_{8} \mathrm{H}_{6} \mathrm{~N}_{4} \mathrm{O}_{5}$ & $\mathrm{C}_{8} \mathrm{H}_{6} \mathrm{~N}_{4} \mathrm{O}_{5}$ \\
\hline Crystal system & Monoclinic & Triclinic & Monoclinic & Monoclinic \\
\hline Space group & $P 21 / \mathrm{c}$ & $P-1$ & $P 21 / \mathrm{c}$ & $P 21 / \mathrm{c}$ \\
\hline $\mathrm{a} / \AA$ & $7.845(1)$ & $6.774(1)$ & $7.840(5)$ & 7.849 (3) \\
\hline $\mathrm{b} / \AA ̊$ & $6.462(3)$ & 7.795 (1) & $6.486(1)$ & $6.500(3)$ \\
\hline c/Å & $18.920(4)$ & $9.803(2)$ & $18.911(6)$ & $20.057(7)$ \\
\hline$\alpha /^{\circ}$ & 90.00 & $106.68(1)$ & 90.00 & 90.00 \\
\hline$\beta /^{\circ}$ & $93.18(2)$ & $104.09(2)$ & 93.17 (3) & $109.68(1)$ \\
\hline$\gamma /^{\circ}$ & 90.00 & $92.29(1)$ & 90.00 & 90.00 \\
\hline Volume $/ \AA^{3}$ & 957.7 (5) & 477.560 & $960.2(7)$ & $963.5(7)$ \\
\hline Z & 4 & 2 & 4 & 4 \\
\hline $\mathrm{Dc} / \mathrm{Mg} \cdot \mathrm{m}^{-3}$ & 1.652 & 1.656 & 1.648 & 1.642 \\
\hline CSD ref. code & LABJON & LABJON01 & LABJON02 & This study \\
\hline
\end{tabular}

Table S2. The dihedral angle between the furan and the hydantoin ring designated by $\alpha\left(^{\circ}\right)$.

\begin{tabular}{ccccccc}
\hline Compound & NF-1 & NF-2 & NF-3 & $\mathbf{1}$ & $\mathbf{2}$ & 3.26 \\
\hline$\alpha\left({ }^{\circ}\right)$ & 5.52 & 3.02 & 5.25 & 5.35 & 10.98 \\
\hline
\end{tabular}

